\title{
Modeling Ecosystems Using P Systems: The Bearded Vulture, a Case Study
}

\author{
Mónica Cardona ${ }^{1}$, M. Angels Colomer ${ }^{1}$, Mario J. Pérez-Jiménez ${ }^{2}$, \\ Delfí Sanuy ${ }^{3}$, and Antoni Margalida ${ }^{4}$ \\ ${ }^{1}$ Dept. of Mathematics, University of Lleida \\ Av. Alcalde Rovira Roure, 191. 25198 Lleida, Spain \\ \{mcardona, colomer\} @matematica.udl.es \\ ${ }^{2}$ Research Group on Natural Computing \\ Dept. of Computer Science and Artificial Intelligence, University of Sevilla \\ Avda. Reina Mercedes s/n, 41012 Sevilla, Spain \\ marper@us.es \\ ${ }^{3}$ Dept. of Animal Production, University of Lleida \\ Av. Alcalde Rovira Roure, 191. 25198 Lleida, Spain \\ dsanuy@prodan.udl.cat \\ ${ }^{4}$ Bearded Vulture Study \& Protection Group \\ Adpo. 43 E-25520 El Pont de Suert (Lleida), Spain \\ margalida@inf .entorno.es
}

\begin{abstract}
The Bearded Vulture (Gypaetus barbatus) is an endangered species in Europe that feeds almost exclusively on bone remains of wild and domestic ungulates. In this paper, we present a model of an ecosystem related to the Bearded Vulture in the Pyrenees (NE Spain), by using $\mathrm{P}$ systems. The evolution of six species is studied: the Bearded Vulture and five subfamilies of domestic and wild ungulates upon which the vulture feeds. P systems provide a high level computational modeling framework which integrates the structural and dynamic aspects of ecosystems in a comprehensive and relevant way. $\mathrm{P}$ systems explicitly represent the discrete character of the components of an ecosystem by using rewriting rules on multisets of objects which represent individuals of the population and bones. The inherent stochasticity and uncertainty in ecosystems is captured by using probabilistic strategies. In order to experimentally validate the $\mathrm{P}$ system designed, we have constructed a simulator that allows us to analyze the evolution of the ecosystem under different initial conditions.
\end{abstract}

\section{Introduction}

Animal species are interconnected in a network in which some species depend on others in terms of feeding [10], 26]. Variations in biomass affect the composition of the population structures [24]. In mountain ecosystems, the presence of domestic animals has disrupted the traditional relationships between wild ungulates and their predators $[6$. Animals located at the top of the ecological pyramid are susceptible to the presence and number of these domestic animals. 
The abandonment of dead animals in the mountains is a major source of food for necrophagous species [15. This is the case for the Bearded Vulture (Gypaetus barbatus), a threatened species which feeds on bone remains of domestic and wild ungulates.

The study of population ecology and how species interact with the environment [13] is one aspect of conservation biology of great interest to managers and conservationists 2]. A widespread tool used in this area is the ecological model, which uses mathematical representations of ecological processes [21].

In this study, we design a model that studies the evolution of an ecosystem located in the Pyrenees, taking advantage of the capacity the $\mathrm{P}$ systems to work in parallel. $\mathrm{P}$ systems provide a high level computational modeling framework which integrates the structural and dynamic aspects of ecosystems in a comprehensive and relevant way. $\mathrm{P}$ systems explicitly represent the discrete character of the components of an ecosystem by using rewriting rules on multisets of objects which represent individuals of the population and biomass available. The inherent stochasticity and uncertainty in ecosystems is captured by using probabilistic strategies. The ecosystem included six species: Bearded Vulture as a scavenger (predator) species and the Pyrenean Chamois (Rupicapra pyrenaica), Red Deer (Cervus elaphus), Fallow Deer (Dama dama), Roe Deer (Capreolus capreolus) and Sheep (Ovis capra) as carrion (prey) species. In order to experimentally validate of the $\mathrm{P}$ system designed we have constructed a simulator that allows us to analyze the evolution of the ecosystem under different initial conditions. The Bearded Vulture is an endangered species and so there are many projects that study its behavior and how it is affected by its environment. Thanks to these studies there is a large amount of information available which is required to define the $\mathrm{P}$ system and to validate the results obtained.

The paper is structured as follows. In the next section, basic concepts of the ecosystem to be modeled are introduced. The most outstanding aspects of each species are detailed as well as the interactions among them. In Section 3, a dynamic probabilistic $\mathrm{P}$ system to describe the ecosystem is presented. In order to study the dynamics of the ecosystem, a simulator of that probabilistic $\mathrm{P}$ system is designed in Section 4. The following section is devoted to the analysis of the results produced by the simulator. Finally, conclusions are presented in the last section.

\section{Modeling the Ecosystem}

The ecosystem to be modeled is located in the Catalan Pyrenees, in the Northeast of Spain. This area contains a total of 35 breeding territories that constitutes $34.3 \%$ of the Bearded Vulture's Spanish population in 2007 ( $\mathrm{n}=102)$. See Figure 1 [15].

The ecosystem to be modeled is composed of six species: the Bearded Vulture (predator species) and the Pyrenean Chamois, Red Deer, Fallow Deer, Roe Deer, and Sheep (prey species). Prey species belong to the bovid family, they are herbivores and their bone remains form the basic source of nourishment for the Bearded Vulture in the Pyrenees. 


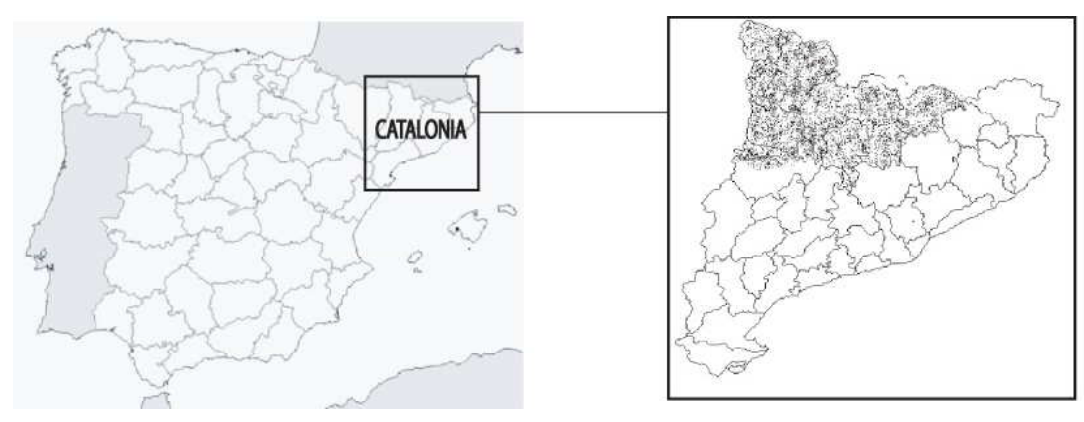

Fig. 1. Regional distribution of the Bearded Vulture in the Catalan Pyrenees

The Bearded Vulture is a cliff-nesting and territorial large scavenger distributed in mountains ranges in Eurasia and Africa. This is one of the rarest raptors in Europe (150 breeding pairs in 2007). This species has a mean lifespan in wild birds of 21.4 years [4. The mean age of first breeding is 8.1 years, whereas the mean age of first successful breeding was 11.4 years [1]. Egg-laying takes place from December to February and after 52-54 days of incubation and after about 120 days of chick-rearing, the chick abandons the nest between June and August [19. Clutch size in this species is usually two eggs, but only one chick survives as a consequence of sibling aggression 18 . The female's annual fertility rate in Catalonia during the last five years is estimated around $38 \%$.

The Bearded Vulture is the only vertebrate that feeds almost exclusively on bone remains. Its main food source is bone remains of dead small and mediumsized animals. In the Pyrenees, the remains of Pyrenean Chamois, Red Deer, Fallow Deer, Roe Deer, and Sheep form $67 \%$ of the vulture's food resources, and the remaining $33 \%$ includes the remains of small sized mammals (e.g., dogs, cats), large mammals (cows, horses), medium sized mammals (e.g., wild boars) and birds [15. A pair of Bearded Vultures needs an average of $341 \mathrm{Kg}$ of bones per year [17, 16 .

During the dispersal period (from fledgling until the birds become territorial at 6 or 7 years), non-adult Bearded Vultures cover large distances surveying different areas. For example, the average surface covered by four young vultures monitored after fledging was $4932 \mathrm{~km}^{2}$ (range 950-10294 km², [23]). Breeding birds are territorial and the approximate home ranges obtained for eight pairs studied varied between $250 \mathrm{~km}^{2}$ and $650 \mathrm{~km}^{2}$. The average annual growth in the population of the Bearded Vultures in the Pyrenees has been estimated at $4-5 \%$. The floating population principally remains in feeding stations situated in the central Pyrenees (Aragon).

The natural behavior of the five bovid species is similar because they are all herbivores and they all reach adult size at one year of age. In general, they reach sexual maturity within two years of birth. Pyrenean Chamois and the Red Deer have a longer life expectancy than Fallow Deer and Roe Deer (for a review of population parameters see $[7, \underline{8},[3,9]$ and $[20)$. The natural mortality rates are similar in all five species in the first year of life it is calculated to be $50 \%$ 
and $6 \%$ during their remaining years. In spite of the great degree of similarity between these five species, important differences exist. For example, some are naturally occurring while others have been introduced by human populations0. It is essential to bear these differences in mind while defining a $\mathrm{P}$ system that can simulate the ecosystem in a reliable way.

Red Deer are appreciated by hunters, not for their meat but as a trophy and so only the males are hunted. This causes the natural evolution of the population to be modified. The hunter only takes the head as a trophy leaving the animal's body in the field. Hence the carcass is eaten by other species and the bone remains may then be eaten by the Bearded Vulture.

Fallow Deer and Roe Deer live in areas that are difficult to reach and for this reason, the Bearded Vulture cannot take advantage of the remains of all of the dead animals of these species.

As sheep [25] are domestic animals, humans exert a high level of control over their populations. The size and growth of the sheep population is limited by the owners of the flocks. The natural average life expectancy of sheep is longer than their actual life expectancy in the field because upon a decrease in fertility rate at the age of eight, they are removed from the habitat. Most of the lambs are sold to market and so they are removed from the habitat in the first year of life. Only $20 \%$ to $30 \%$ of the lambs, mostly females, are left in the field and these are used to replace sheep that have died naturally and those older sheep that have been removed from the flock. The number of animals in the Catalan Pyrenees during the years 1994 and 2008 is shown in Table 1 (see Appendix).

In this study, the feeding of the Bearded Vulture is dependent on the evolution of the $\mathrm{P}$ system. However the $\mathrm{P}$ system does not consider the fact that the availability of food limits the feeding of the herbivores, and so the growth of vegetation is not modeled.

Taking all of this background information into consideration, the following data was required for each species:

- $I_{1}$ : Age at which adult size is reached. Age at which the animal consumes as much as an adult. At this age the animal will have surpassed the critical early phase during which mortality rate is high;

$-I_{2}$ : Age at which it begins to be fertile;

$-I_{3}$ : Age at which it stops being fertile;

$-I_{4}$ : Average life expectancy;

- $I_{5}$ : Fertility ratio (number of descendants by 100 fertile females);

$-I_{6}$ : Mortality ratio in first years, age $<I_{1}$ (this quantity is expressed in terms of percentage);

- $I_{7}$ : Mortality ratio in adult animals, age $\geq I_{1}$ (this quantity is expressed in terms of percentage);

- $I_{8}$ : Ratio of females in the population (this quantity is expressed in terms of percentage).

The required information about each species is shown in Table 2 (see the Appendix). 
When an animal dies, the weight of the bones that it leaves behind is around $20 \%$ of its total weight. Table 3 (see Appendix) shows the average weight of each animal as well as the weight of bones left behind. In the case of Fallow Deer and Roe Deer, the value of the weight of bones is then multiplied by 0,2 (20\%) which is the portion of bones from which the Bearded Vulture may benefit.

In the $\mathrm{P}$ system only Bearded Vultures older than 8 are considered, because younger ones are floating birds. There are seven feeding stations in Catalonia which provide around $10500 \mathrm{~kg}$ of bone remains annually. These artificial feeding sites have not been considered in the study and most of the floating birds feed at these sites.

\section{A P System Based Model of the Ecosystem}

Membrane computing is a branch of Natural Computing that was initiated at the end of 1998 by Gh. Păun (by a paper circulated at that time on the web and published in 2000 [22]). Since then it has received important attention from the scientific community. Details can be found on the web page http://ppage.psystems.eu/

In short, one abstracts computing models from the structure and the functioning of living cells, as well as from the organization of cells in tissues, organs, and other higher order structures. The main components of such a model are a cell-like membrane structure, in the compartments of which one places multisets of symbol-objects which evolve in a synchronous maximally parallel manner according to given evolution rules, also associated with the membranes.

The semantic of the $\mathrm{P}$ systems is defined as follows: a configuration of a $\mathrm{P}$ system consists of a membrane structure and a family of multisets of objects associated with each region of the structure. At the beginning, there is a configuration called the initial configuration of the system.

In each time unit we can transform a given configuration to another one by applying the evolution rules to the objects placed inside the regions of the configurations, in a non-deterministic, and maximally parallel manner (the rules are chosen in a non-deterministic way, and in each region all objects that can evolve must do so). In this way, we obtain transitions from one configuration of the system to the next.

A computation of the system is a (finite or infinite) sequence of configurations such that each is obtained from the previous by a transition, and shows how the system is evolving. A computation that reaches a configuration in which no more rules can be applied to the existing objects is called a halting computation. The result of a halting computation is usually encoded by the multiset associated with a specific output membrane (or the environment) in the final configuration.

In this section, we present a model of the ecosystem described in Section 2 by means of probabilistic P systems. We will study the behavior of this ecosystem under diverse initial conditions.

First, we define the $\mathrm{P}$ systems based framework (probabilistic P systems), where additional features such as two electrical charges which describe specific properties in a better way, are used. 
Definition 1. A probabilistic $P$ system of degree $n$ is a tuple

$$
\Pi=\left(\Gamma, \mu, w_{1}, \ldots, w_{n}, R,\left\{c_{r}\right\}_{r \in R}\right),
$$

where:

- $\Gamma$ is the alphabet (finite and nonempty) of objects (the working alphabet);

$-\mu$ is a membrane structure, consisting of $n$ membranes, labeled $1,2, \ldots, n$. The skin membrane is labeled by 1. We also associate electrical charges with membranes from the set $\{0,+\}$, neutral and positive;

$-w_{1}, \ldots, w_{n}$ are strings over $\Gamma$, describing the multisets of objects initially placed in the $n$ regions of $\mu$;

$-R$ is a finite set of evolution rules. An evolution rule associated with the membrane labeled by $i$ is of the form $r: u[v]_{i} \stackrel{c_{r}}{\longrightarrow} u^{\prime}\left[v^{\prime}\right]_{i}$, where $u, v, u^{\prime}, v^{\prime}$ are a multiset over $\Gamma$ and $c_{r}$ is a real number between 0 and 1 associated with the rule.

We assume that a global clock exists, marking the time for the whole system (for all compartments of the system); that is, all membranes and the application of all rules are synchronized.

The $n$-tuple of multisets of objects present at any moment in the $n$ regions of the system constitutes the configuration of the system at that moment. The tuple $\left(w_{1}, \ldots, w_{n}\right)$ is the initial configuration of the system.

The $\mathrm{P}$ system can pass from one configuration to another by using the rules from $R$ as follows: at each transition step, the rules to be applied are selected according to the probabilities assigned to them, and all applicable rules are simultaneously applied and all occurrences of the left-hand side of the rules are consumed, as usual.

\subsection{The Model}

Our model consists of the following probabilistic P system of degree 2 with two electrical charges (neutral and positive):

$$
\Pi=\left(\Gamma, \mu, w_{1}, w_{2}, R,\left\{c_{r}\right\}_{r \in R}\right),
$$

where:

- In the alphabet $\Gamma$, we represent the six species of the ecosystem (index $i$ is associated with the species and index $j$ is associated with their age, and the symbols $X, Y$ and $Z$ represent the same animal but in different states); it also contains the auxiliary symbol $B$, which represents $0.5 \mathrm{~kg}$ of bones, and $C$, which allows a change in the polarization of the membrane labeled by 2 at a specific stage.

$$
\Gamma=\left\{X_{i j}, Y_{i j}, Z_{i j}: 1 \leq i \leq 7,0 \leq j \leq k_{i, 4}\right\} \cup\{B, C\}
$$

- In the membrane structure, we consider two regions, $\left.\mu=[\text { [ }]_{2}\right]_{1}$ (neutral polarization will be omitted): 
- the skin region where the objects that represent animals evolve according to the rules of reproduction and mortality.

- an inner membrane where the objects associated with animals evolve according to the feeding rules.

- In $w_{1}$ and $w_{2}$, we specify the initial number of objects present in each region (encoding the initial population and the initial food);

- $w_{1}=\left\{X_{i j}^{q_{i j}} \mid 1 \leq i \leq 7,0 \leq j \leq k_{i, 4}\right\}$, where the multiplicity $q_{i j}$ indicates the number of animals, of species $i$ whose age is $j$ that are initially present in the ecosystem;

- $w_{2}=\left\{C B^{\alpha}\right\}$, where $\alpha$ is defined as follows:

$$
\alpha=\left\lceil\sum_{j=1}^{21} q_{1 j} \cdot 1.10 \cdot 682\right\rceil
$$

Value $\alpha$ represents an external contribution of food which is added during the first year of study so that the Bearded Vulture survives. In the formula, $q_{1 j}$ represents the number of $j$ years of age of Bearded Vultures, the finality of constant factor 1.10 is to guarantee enough food for $10 \%$ population growth. At present, the population growth is estimated an average $4 \%$, but this value can reach higher values. Thus, to avoid problems related with the underestimation of this value the first year we estimated the population growth (overestimated) at 10\%. The constant value 682 represents the amount of food needed per year for a Bearded Vulture pair to survive.

- The set $R$ of evolution rules consists of:

- Reproduction-rules.

Adult males:

$* r_{0} \equiv\left[X_{i j} \stackrel{\left(1-k_{i, 13}\right) \cdot\left(1-k_{i, 15}\right)}{\longrightarrow} Y_{i j}\right]_{1}, 1 \leq i \leq 7, k_{i, 2} \leq j \leq k_{i, 4}$.

Adult females that reproduce:

$* r_{1} \equiv\left[X_{i j} \stackrel{{ }_{i, 5} \cdot k_{i, 13} \cdot\left(1-k_{i, 15}\right)}{\longrightarrow} Y_{i j} Y_{i 0}\right]_{1}, 1 \leq i \leq 7, k_{i, 2} \leq j<k_{i, 3}$.

Fertile adult females that do not reproduce:

$* r_{2} \equiv\left[X_{i j} \stackrel{\left(1-k_{i, 5}\right) \cdot k_{i, 13} \cdot\left(1-k_{i, 15}\right)}{\longrightarrow} Y_{i j}\right]_{1}, 1 \leq i \leq 7, k_{i, 2} \leq j<k_{i, 3}$.

Not fertile adult females:

$* r_{3} \equiv\left[X_{i j} \stackrel{{ }_{i, 13 \cdot\left(1-k_{i, 15}\right)}^{\longrightarrow}}{\longrightarrow} Y_{i j}\right]_{1}, 1 \leq i \leq 7, k_{i, 3} \leq j \leq k_{i, 4}$.

Young animals that do not reproduce:

$* r_{4} \equiv\left[X_{i j} \stackrel{1-k_{i, 15}}{\longrightarrow} Y_{i j}\right]_{1}, 1 \leq i \leq 7,0 \leq j<k_{i, 2}$.

- Growth rules.

$* r_{5} \equiv\left[X_{i j} \stackrel{\left(k_{i, 6}+k_{i, 10}\right) \cdot k_{i, 15}}{\longrightarrow} Y_{i k_{i, 2}} Y_{i j}\right]_{1}, 1 \leq i \leq 7, k_{i, 2} \leq j<k_{i, 4}$.

$* r_{6} \equiv\left[X_{i j} \stackrel{\left(1-k_{i, 6}-k_{i, 10}\right) \cdot k_{i, 15}}{\longrightarrow} Y_{i j}\right]_{1}, 1 \leq i \leq 7, k_{i, 2} \leq j<k_{i, 4}$.

$* r_{7} \equiv\left[X_{i j} \stackrel{k_{i, 6} \cdot k_{i, 15}}{\longrightarrow} Y_{i k_{i, 2}} Y_{i j}\right]_{1}, 1 \leq i \leq 7, j=k_{i, 4}$.

$* r_{8} \equiv\left[X_{i j} \stackrel{\left(1-k_{i, 6}\right) \cdot k_{i, 15}}{\longrightarrow} Y_{i j}\right]_{1}, 1 \leq i \leq 7, j=k_{i, 4}$. 
- Mortality rules.

- Young animals

Those which survive:

$* r_{9} \equiv Y_{i j}[]_{2} \stackrel{1-k_{i, 7}-k_{i, 8}}{\longrightarrow}\left[Z_{i j}\right]_{2}, 1 \leq i \leq 7,0 \leq j<k_{i, 1}$.

Those which die:

$* r_{10} \equiv Y_{i j}[]_{2} \stackrel{k_{i, 8}}{\longrightarrow}\left[B^{k_{i, 11}}\right]_{2}, 1 \leq i \leq 7,0 \leq j<k_{i, 1}$.

Those which are retired from the ecosystem:

$* r_{11} \equiv\left[Y_{i j} \stackrel{k_{i, 7}}{\longrightarrow} \lambda\right]_{1}, 1 \leq i \leq 7,0 \leq j<k_{i, 1}$.

- Adult animals that don't arrive at an average life expectancy .

Those which survive:

$* r_{12} \equiv Y_{i j}[]_{2} \stackrel{1-k_{i, 10}}{\longrightarrow}\left[Z_{i j}\right]_{2}, 1 \leq i \leq 7, k_{i, 1} \leq j<k_{i, 4}$.

Those which die:

$* r_{13} \equiv Y_{i j}[]_{2} \stackrel{k_{i, 10}}{\longrightarrow}\left[B^{k_{i, 12}}\right]_{2}, 1 \leq i \leq 7, k_{i, 1} \leq j<k_{i, 4}$.

- Animals that arrive at an average life expectancy:

Those which growth population depend on the fertility ratio and die in the ecosystem:

$* r_{14} \equiv Y_{i j}[]_{2} \stackrel{\left(1-k_{i, 15}\right) \cdot\left(k_{i, 9}+\left(1-k_{i, 9}\right) \cdot k_{i, 10}\right)}{\longrightarrow}\left[B^{k_{i, 12}}\right]_{2}, 1 \leq i \leq 7, j=k_{i, 4}$.

Those which growth population depend on the fertility ratio and are retired of the ecosystem:

$* r_{15} \equiv\left[Y_{i j} \stackrel{\left(1-k_{i, 15}\right) \cdot\left(1-k_{i, 9}\right) \cdot\left(1-k_{i, 10}\right)}{\longrightarrow} \lambda\right]_{1}, 1 \leq i \leq 7, j=k_{i, 4}$.

Those which growth population not depend on the fertility ratio:

$* r_{16} \equiv Y_{i j}[]_{2} \stackrel{k_{i, 15}}{\longrightarrow}\left[Z_{i k_{i, 2}}\right]_{2}, 1 \leq i \leq 7, j=k_{i, 4}$.

- Feeding rules.

$* r_{17} \equiv\left[Z_{i j} B^{k_{i, 14}}\right]_{2} \rightarrow X_{i j+1}[]_{2}^{+}, 1 \leq i \leq 7,0 \leq j \leq k_{i, 4}$.

- Balance rules. The propose of this rules is to make a balance at the end of the year. It is to say the leftover food not served for the next year, so it is necessary eliminate, and if the amount of food not is enough some animals die.

Elimination of remaining bones:

* $r_{18} \equiv[B]_{2}^{+} \rightarrow[]_{2}$.

Adult animals that die because they have not enough food:

$* r_{19} \equiv\left[Z_{i j}\right]_{2}^{+} \rightarrow\left[B^{k_{i, 12}}\right]_{2}, 1 \leq i \leq 7, k_{i, 1} \leq j \leq k_{i, 4}$

Young animals that die because they have not enough food:

* $r_{20} \equiv\left[Z_{i j}\right]_{2}^{+} \rightarrow\left[B^{k_{i, 11}}\right]_{2}, 1 \leq i \leq 7, j<k_{i, 1}$

If the food is equal to the necessary the object $\mathrm{C}$ allow to change the polarization.

$* r_{21} \equiv[C]_{2}^{+} \rightarrow[C]_{2}$.

The constants associated with the rules have the following meaning:

$-k_{i, 1}$ : Age at which adult size is reached. This is the age at which the animal consumes food as an adult does, and at which, if the animal dies, the amount of biomass it leaves behind is similar to the total left by an adult. Moreover, at this age it will have surpassed the critical early phase during which the mortality rate is high. 
$-k_{i, 2}$ : Age at which it begins to be fertile.

$-k_{i, 3}$ : Age at which it stops being fertile.

$-k_{i, 4}$ : Average life expectancy in the ecosystem.

$-k_{i, 5}$ : Fertility ratio (number of descendants by fertile females).

$-k_{i, 6}$ : Population growth (this quantity is expressed in terms of 1 ).

$-k_{i, 7}$ : Animals retired from the ecosystem in the first years, age $<k_{i, 1}$ (this quantity is expressed in terms of 1 ).

$-k_{i, 8}$ : Natural mortality ratio in first years, age $<k_{i, 1}$ (this quantity is expressed in terms of 1 ).

$-k_{i, 9}: 0$ if the live animals are retired at age $k_{i, 4}$, in other cases, the value is 1 .

$-k_{i, 10}$ : Mortality ratio in adult animals, age $\geq k_{i, 1}$ (this quantity is expressed in terms of 1 ).

$-k_{i, 11}$ : Amount of bones from young animals, age $<k_{i, 1}$.

$-k_{i, 12}$ : Amount of bones from adult animals, age $\geq k_{i, 1}$.

$-k_{i, 13}$ : Proportion of females in the population (this quantity is expressed in terms of 1$)$.

$-k_{i, 14}$ : Amount of food necessary per year and breeding pair ( 1 unit is equal to $0.5 \mathrm{~kg}$ of bones).

$-k_{i, 15}$ : Equal to 0 when the species experience natural growth (animals that remain in the same territory throughout their lives) and is equal to 1 when animals are nomadic (the Bearded Vulture moves from one place to another until it is 6-7 years old, at which point it remains in one location).

Values for each species are shown in Table 4 (see Appendix). Most values in that table are equal to those in Table 2 (see Appendix), but it is necessary to

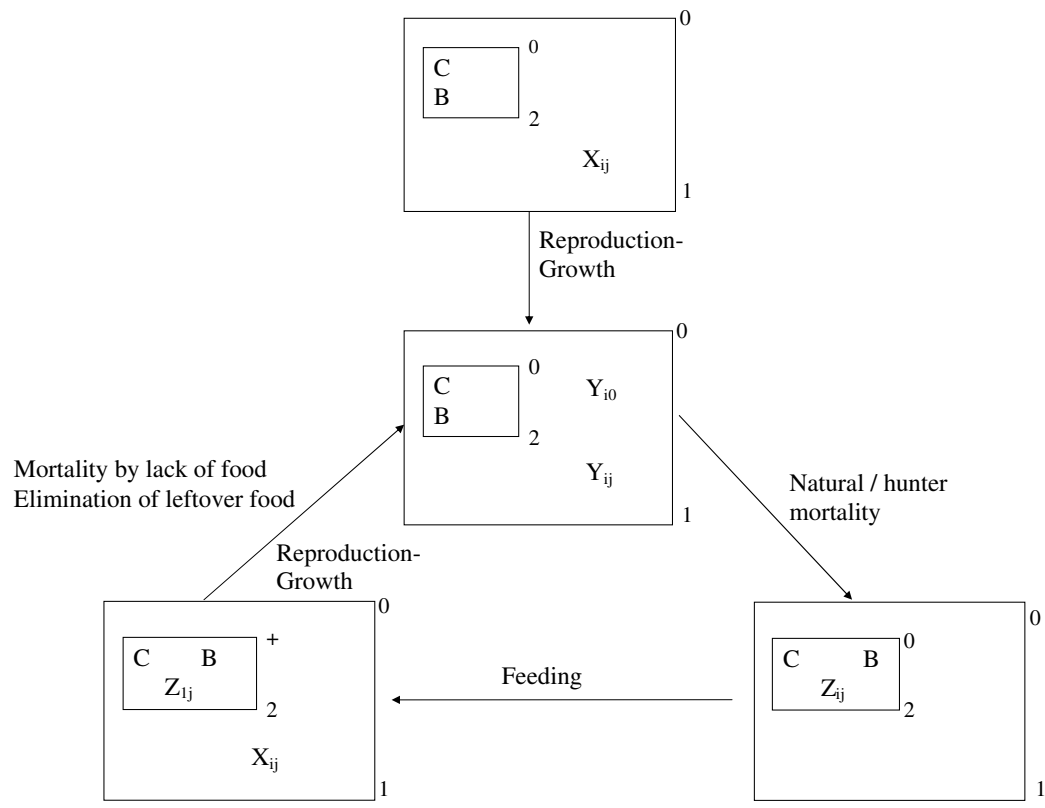

Fig. 2. Structure of the $\mathrm{P}$ system running 
remark on values $k_{4,10}$ and $k_{1,14}$. Value $k_{4,10}$ is obtained by adding $6 \%$ of natural mortality to $30 \%$ of animals killed by hunters. Value $k_{1,14}$ is $67 \%$ of 682 units $(341 \cdot 2)$ which is the food the Bearded Vulture obtains from the other five species of ungulates modeled in the ecosystem.

The $\mathrm{P}$ system designed implements a four-stage-running. The first one is devoted to the reproduction of the diverse species in the ecosystem. Then, the animals' mortality is analyzed according to different criteria. The third stage analyzes the amount of food in the ecosystem. In the last stage, the removal of animals due to lack of food takes place. These stages are depicted in Figure 2.

\section{A Simulator}

In order to study the dynamics of the species that belong to the ecosystem, we have designed a simulator written in $\mathrm{C}++$ language. This program runs on a $\mathrm{PC}$.

In the simulation, the objects that encode the species and the age are represented by two vectors that are related through the number assigned to each animal of the ecosystem. The objects of the $\mathrm{P}$ system evolve in a random way; this stochasticity is implemented by generating random numbers between 1 and 100, according to a uniform distribution. One of the generated numbers is assigned to each animal. Then, the animal evolves according to the assigned number and the constant probability. For example, when the probability of surviving is $70 \%$, the animal will die if the assigned number is higher than 70 .

The input of the program consists of the parameters of each species that are considered in the $\mathrm{P}$ system and the number of animals of each species and age that are present at time zero. The output is the number and age of animals of each species that are present every year after completing the following processes: reproduction, mortality and feeding.

In nature, an ecosystem is governed by nondeterminism, and this implies a complex mathematical model. Nevertheless, all the processes that are carried out have an important degree of randomness. This randomness can be predicted and can be quantified at every moment and situation within the ecosystem.

The program has been structured in four modules which correspond to each of the stages in which the $\mathrm{P}$ system is implemented.

- Reproduction. The inputs are the age at which each species begins to be fertile, the age at which it stops being fertile, the fertility rate, and the proportion of females of the species. This module also requires the total number of existing animals and the distribution of these animals in terms of species and ages. The output of this module is the number and age of animals of each species.

The population growth of the Bearded Vulture is not obtained from the natural reproduction of the animals in the ecosystem but it depends on the floating population and the environment. 
The annual growth ratio has been obtained by R. Heredia [11] in an experimental way. Another input of this module is the growth percentage with respect to the total population, and the output (as in the case of animals natural reproduction) is the number of animals at each age.

- Mortality. The inputs are the mortality rate based on the age, the average life expectancy of each species, and finally the weight of bones left by the dead animal which is dependent on its age. Once again, this module also requires the total number of animals and their distribution in terms of species and ages. As with the other modules, the output of this module is the number and age of animals of each species when the process is completed. Another output of this module is the amount of food that is generated in terms of the weight of bones produced that provides the Bearded Vulture's basic source of nourishment.

- Feeding. The inputs are the amount of food available in the ecosystem and the annual amount of food that is necessary for the animal to survive under suitable conditions, in other words: conditions under which the animals are not debilitated and do not suffer the consequent effects on their capabilities. As was seen in the previous modules, inputs are generated by the P system itself as it quantifies objects representing the number of animals of each existing species and age. Once again, the output of this module is the number and age of animals of each species.

- Elimination of unused leftover food and the animal mortality from insufficient feeding. The input of this module is part of output of the feeding module. The aim of this process is to eliminate the number of animals that were not able to find the necessary amount of food for their survival, and also to consider the amount of leftover food that is degraded with time and that therefore ceases to play a role in the model. The animals that die due to a lack of food are transformed into bones that can then be eaten by the Bearded Vulture. The output of this module is an amount of food in the form of bones that is available to the Bearded Vulture.

The unit of reference used in this study is the year: that is, the food consumed throughout an annual period is given at one single point in time, and with one application of each rule. The mortality of animals in an ecosystem is also a process that is carried out in a continuous way, throughout the year. However, reproduction is an activity that takes place at a specific time of the year, and moreover, takes place at the same time for all of the species considered in this study. It will be necessary to verify whether the one year unit of time chosen is correct or whether a shorter unit of time should be used in the $\mathrm{P}$ system. It is also necessary to check the robustness of the proposed model and to do this, it is run a second time with a modified order of application of the four processes modules. Given independence of the four modules that form the $\mathrm{P}$ system, it would be a simple exercise to run probability experiments with each module. 


\section{Results and Discussion}

We have run our simulations using a program written in $\mathrm{C}++$ language incorporating a specification of our model. We have considered the year as the unit of time, so it has been necessary to discretize feeding and mortality variables.

As shown in Table 1 (see Appendix), data on the current number of animals in the Catalan Pyrenees do not specify the ages of animals. An age distribution has been estimated considering the different constants that affect the animals throughout their life. These constants are fertility rate, mortality rate and percentage of females in the population. We have obtained two estimations, one for the year 1994 which has been used for the experimental validation, shown in Table 5 (see Appendix), and another for the year 2008 which has been used to study the robustness of the $\mathrm{P}$ system, shown in Table 6 (see Appendix).

\subsection{Robustness}

First, we have studied the robustness of our $\mathrm{P}$ system model with respect to several parameters.

According to the design of the $\mathrm{P}$ system, reproduction rules have a higher priority than mortality rules. Subsequently, the robustness of the model regarding the change of that priority is analyzed. For that reason, two variants of the simulator have been studied changing the order of the corresponding modules. This fact can be implemented in the $\mathrm{P}$ system by changing variable $X$ to variable $Y$ in the initial multiset $\mathcal{M}_{1}$.

In both cases, the simulator was run 10 times until it covered a period of 20 years, the input being the number of animals in 2008 .

In Figure 3, solid lines and dashed lines represent the population dynamics when the simulator modules are applied following the orders reproductionmortality-feeding and mortality-feeding-reproduction, respectively. Taking into account that the $\mathrm{P}$ system behavior is similar in both cases, it can be deduced that our model is robust with regard to the properties considered.

\subsection{Experimental Validation}

Let us suppose that we are studying a phenomenon for which we have (a sufficient amount of) data experimentally obtained (in the laboratory, through field-work, etc.) from some prefixed conditions. Let us suppose that we design a computational device trying to capture the most relevant facts, and we have a program which allows us to run simulations. We can say the model is experimentally validated if the results obtained with the simulator (from initial configurations corresponding to the prefixed conditions) are in agreement with the experimental data.

It should be noted that Table 1 (see Appendix) shows those data experimentally obtained corresponding to the years from 1994 to 2008 (the input being the number of animals in 1994) covering a period of 14 years. We have run our simulator 10 times as it supposes a reduction of $70 \%$ of the deviation.

Table 7 (see Appendix) and Figure 4 show the difference between the average number of animal species obtained with the simulator compared with the censuses 

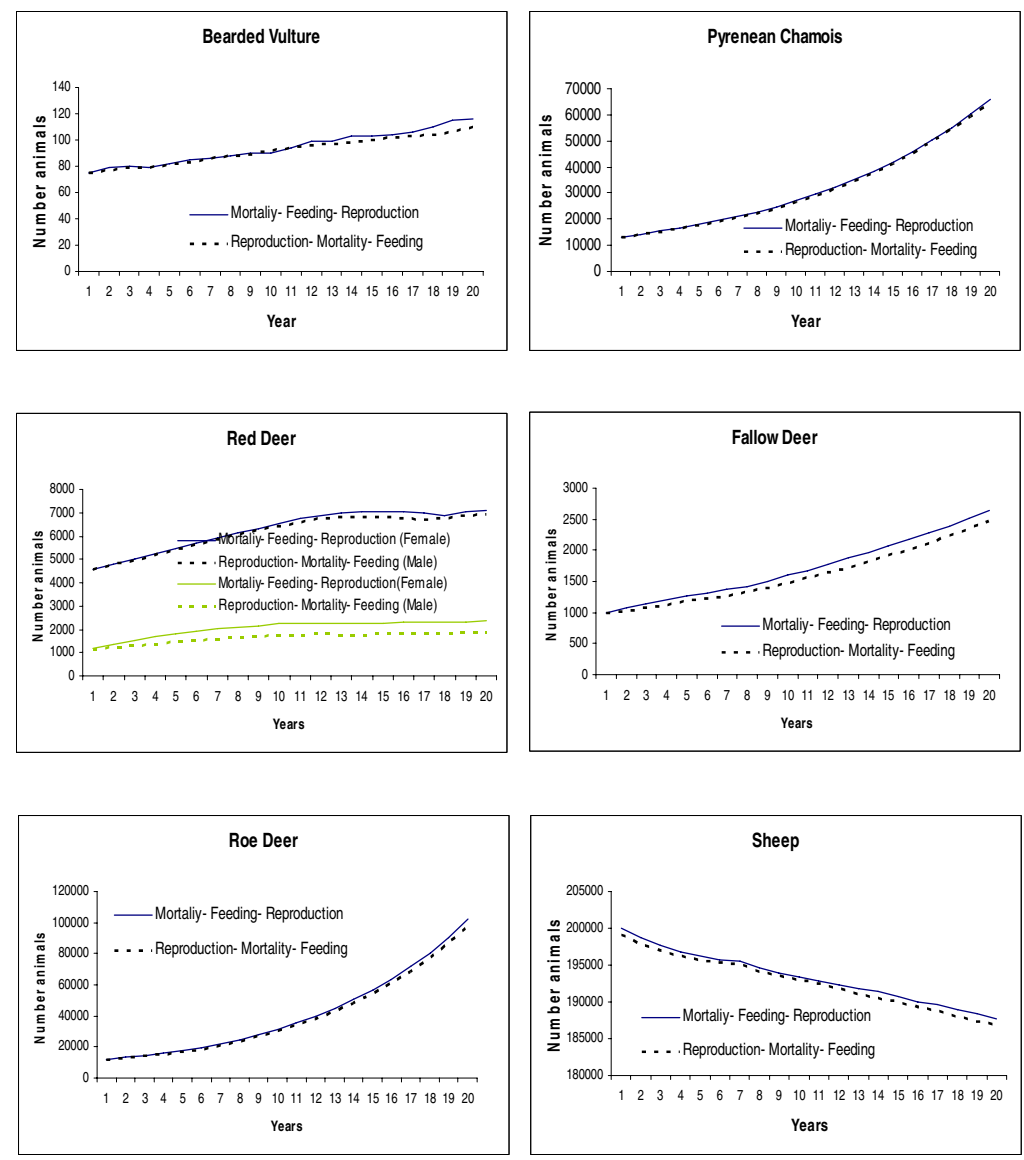

Fig. 3. Robustness of the ecosystem

estimated for 2008. In 2004, the Pyrenean Chamois species was affected by a disease which led to a decrease in the population to 10000 animals. In the third column of that table, the evolution of the $\mathrm{P}$ system is shown without taking into account this piece of information, while in the fourth column it has been considered.

Figure 5 shows the deviation and the coefficient of variation (percentage of deviation with respect to the average) for every year of the simulated data. The deviation increases as we move away from the initial year. Therefore, the noise is greater when we make predictions in the long term. The coefficient of variation obtained in the species studies over 14 years does not exceed the $14 \%$ for the Bearded Vulture and the $5 \%$ for the rest of the species. In the case of the Bearded Vulture, the value is higher than the others due to the low number of breeding pairs of the Bearded Vulture.

The proposed $\mathrm{P}$ system can be considered a good model for the study of the evolution of an ecosystem. Variations noticed among the available data regarding 


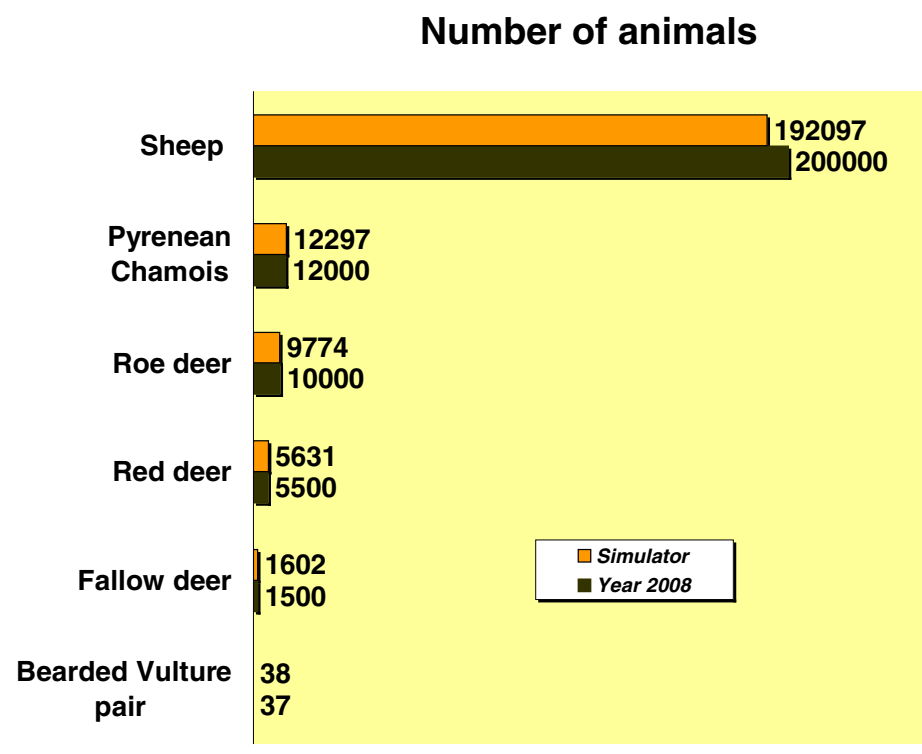

Fig. 4. Average number of animals obtained with the simulator in comparison with the censuses estimated for 2008

the number of animals of each species from 1994 to 2008 (see Table 1) (see Appendix) are of almost no importance if we take into account that these data are taken from estimated censuses and are never exact. Under the same conditions as a starting point, the ecosystem has a certain behavior pattern as it evolves, showing variations inherent to probabilistic systems.

The very important factor of population density was not considered in the model of the ecosystem. In this sense, as has been documented in other raptor species, density dependence and environmental stochasticity are both potentially important processes influencing population demography and long-term population grow [12. This is why the population of some of the species such as Roe Deer, Fallow Deer and Chamois may grow exponentially reaching values which cannot be obtained in the ecosystem. It is well-known, for example, that when a population of Red Deer reaches a level of 15000 animals, a regulation process begins that imposes a drastic decrease of the population to 1000 individuals. Hence, if density are not taken into account, it may not be suitable for the study of ecosystem dynamics in the long-term.

Neither ungulates' feeding behavior nor their population density have been taken into account. This implies an exponential growth of ungulate species constituting the basic food source for the Bearded Vulture. Consequently, there is a continuous growth in the number of pairs of Bearded Vultures. According to some researchers [14, the estimated maximum number of pairs of Bearded Vultures within the area under study is about fifty. Higher numbers of pairs 

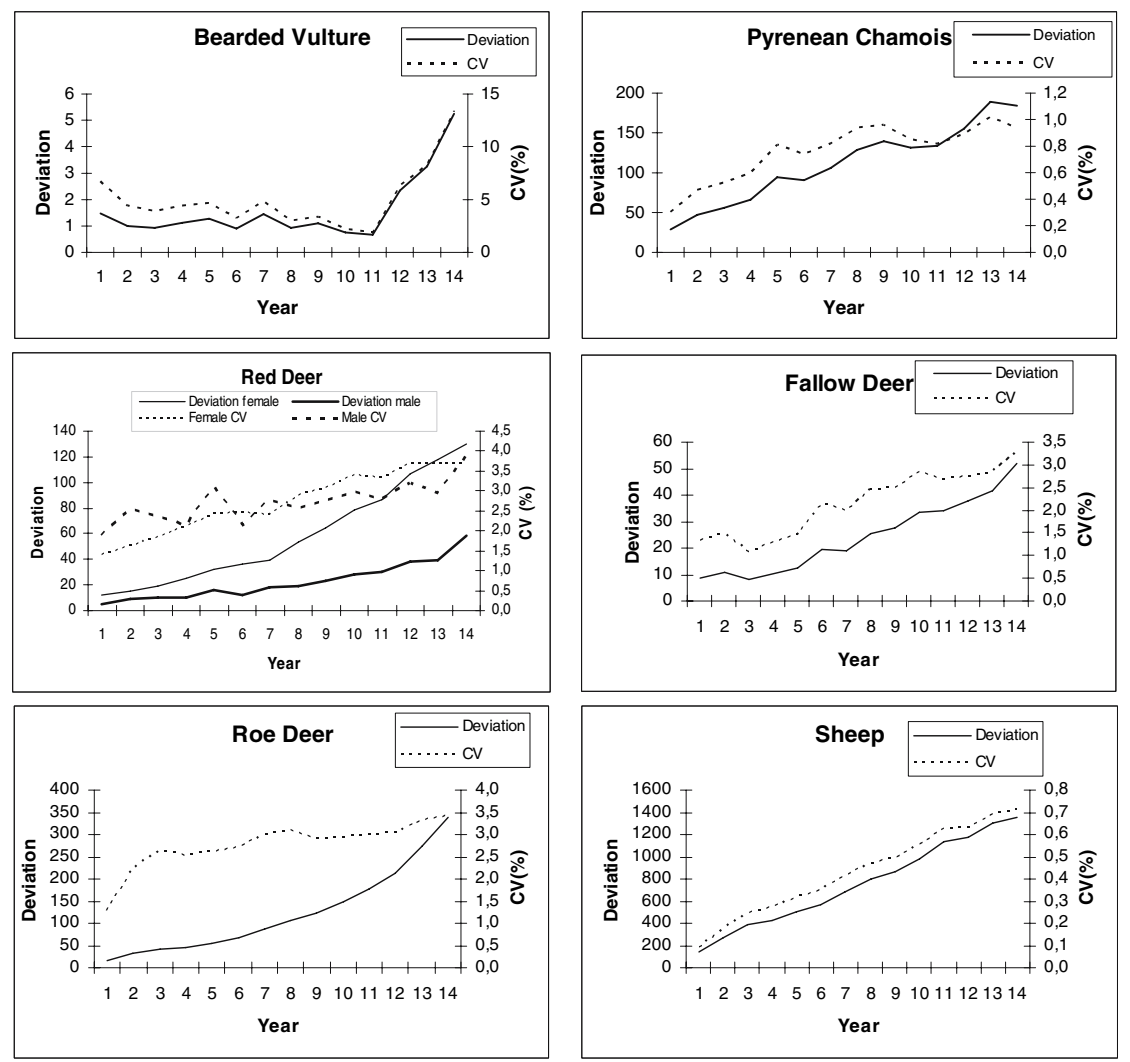

Fig. 5. Deviation and Coefficient of Variation

would lead to competition and a subsequent decrease in the population down to values that the ecosystem can handle.

\section{Conclusions and Future Work}

A probabilistic $\mathrm{P}$ system which models an ecosystem related to the Bearded Vulture located in the Catalan Pyrenees has been presented.

By using this $\mathrm{P}$ system, it has been possible to study the dynamics of the ecosystem modifying the framework in order to analyze how the ecosystem would evolve if different biological factors were modified either by nature or through human intervention.

A simulator of the $\mathrm{P}$ system has been designed and the robustness of the model with respect to the order of application of different rules, has been shown.

Since the $\mathrm{P}$ system does not consider levels of population density, an exponential growth of populations of species is obtained. In future work, this factor and other parameters (i.e., the amount of food of the herbivorous species, the climatic changes in the ecosystem, etc.) should be considered. 
In order to obtain a model which allows us to study the evolution of an ecosystem in the long-term, it is necessary to take into account certain biological factors such as the following:

- Maximum population density for each species.

- Available feeding in the area in which the ungulates may feed.

- Amount of food eaten daily by each of the ungulate species considering their age.

Moreover, under adequate environmental conditions, the species exhibits a certain behavior such that some values of the biological parameters can be accepted. When essential environmental conditions such as temperature and rainfall are not ideal, biological constants change as a reaction to the environment. A model based on Markov chains in order to model temperature and rainfall can be accepted. $\mathrm{P}$ systems modeling Markov chains were previously presented in [5] and they should be considered in order to improve some results.

In future work, we will also try to model interactions between neighboring ecosystems.

Acknowledgements. M.J. Pérez-Jiménez acknowledges the support of the project TIN2006-13425 of the Ministerio de Educación y Ciencia of Spain, cofinanced by FEDER funds, and of the Project of Excellence TIC 581 of the Junta de Andalucia.

Financial support for A. Margalida was obtained from the Departament de Medi Ambient i Habitatge of Generalitat de Catalunya.

\section{References}

1. Antor, R.J., Margalida, A., Frey, H., Heredia, R., Lorente, L., Sesé, J.A.: Age of first breeding in wild and captive populations of Bearded Vultures (Gypaetus barbatus). Acta Ornithologica 42, 114-118 (2007)

2. Begon, M., Harper, J.L., Townsend, C.R.: Ecology: Individuals, Populations and Communities. Blackwell Scientific Publications Inc., Oxford (1988)

3. Braza, F., San José, C., Blom, A., Cases, V., García, J.E.: Population parameters of fallow deer at Doñana National Park (SW Spain). Acta Theriol. 35, 277-288 (1990)

4. Brown, C.J.: Population dynamics of the bearded vulture Gypaetus barbatus in southern Africa. African J. Ecology 35, 53-63 (1997)

5. Cardona, M., Colomer, M.A., Pérez-Jímenez, M.J., Zaragoza, A.: Handling markov chains with membrane computing. In: Calude, C.S., Dinneen, M.J., Păun, G., Rozenberg, G., Stepney, S. (eds.) UC 2006. LNCS, vol. 4135, pp. 72-85. Springer, Heidelberg (2006)

6. Chocarro, C., Fanlo, R., Fillat, F., Marín, P.: Historical evolution of natural resource use in the central Pyrenees of Spain. Mountain Research And Development 10, 257-265 (1990)

7. Clutton-Brock, T., Guinness, F.E., Albon, S.D.: Red deer: Behavior and Ecology of Two Sexes. Edinburgh University Press, Edinburgh (1982)

8. García-González, R., Herrero, J., Hidalgo, R.: Estimación puntual de diversos parámetros poblacionales y distributivos del sarrio en el Pirineo Occidental. Pirineos 35, 53-63 (1985) 
9. Garin, I., Herrero, J.: Distribution, abundance and demographic parameters of the Pyrenean Chamois (Rupicapra p. pyrenaica ) in Navarre, Western Pyreness. Mammalia 61, 55-63 (1997)

10. Harvey, P.H., Purvis, A.: Understanding the ecological and evolutionary reasons for life history variation: mammals as a case study. In: McGlade, J. (ed.) Advanced Ecological Theory: Principles and Applications, pp. 232-247. Blackwell Science Publications, Oxford (1999)

11. Heredia, R.: Status y distribución del quebrantahuesos en España y diagnóstico de la situación de la población en la UE. In: Margalida, A., Heredia, R. (eds.) Biología de la conservación del quebrantahuesos Gypaetus barbatus en España, Organismo Autónomo Parques Nacionales, Madrid (2005)

12. Krüger, O.: Long-term demographic analysis in goshawk. Accipiter gentilis: the role of density dependence and stochasticity. Oecologia 152, 459-471 (2008)

13. Margalef, R.: Ecologa. Universidad Nacional de Educación a Distancia, Madrid (1977)

14. Margalida, A., Donázar, J.A., Bustamante, J., Hernández, F.J., Romero-Pujante, M.: Application of a predictive model to detect long-term changes in nest-site selection in the Bearded Vulture Gypaetus barbatus: conservation in relation to territory shrinkage. Ibis 150, 242-249 (2008)

15. Margalida, A., Garcí, D., Cortés-Avizanda, A.: Factors influencing the breeding density of Bearded Vultures, Egyptian Vultures and Eurasian Griffon Vultures in Catalonia (NE Spain): management implications. Animal Biodiversity and Conservation 30, 189-200 (2007)

16. Margalida, A., Mañosa, S., Bertran, J., Garcıla, D.: Biases in studying the diet of the Bearded Vulture. The Journal of Wildlife Management 71, 1621-1625 (2006)

17. Margalida, A., Bertran, J., Boudet, J.: Assessing the diet of nestling Bearded Vultures: a comparison between direct observation methods. Journal of Field Ornithology $76,40-45$ (2005)

18. Margalida, A., Bertran, J., Boudet, J., Heredia, R.: Hatching asynchrony, sibling aggression and cannibalism in the Bearded Vulture (Gypaetus barbatus). Ibis 146, 386-393 (2004)

19. Margalida, A., García, D., Bertran, J., Heredia, R.: Breeding biology and success of the Bearded Vulture Gypaetus barbatus in the eastern Pyrenees. Ibis 145, 244-252 (2003)

20. Mateos-Quesada, P., Carranza, J.: Reproductive patterns of roe deer in central Spain. Etologa 8, 9-12 (2000)

21. McCallum, H.: Population parameters: estimation for ecological models. Blackwell Science Publications, Oxford (2000)

22. Păun, G.: Computing with membranes. J. Computer and System Sci. 61, 108-143 (2000)

23. Sunyer, C.: El periodo de emancipación en el Quebrantahuesos: consideraciones sobre su conservación. In: Heredia, R., Heredia, B. (eds.) El Quebrantahuesos (Gypaetus barbatus) en los Pirineos, Colección Técnica, Madrid, pp. 47-65 (1991)

24. Tilman, D.: Resource Competition and Community Structure. Princeton University Press, Princeton (1982)

25. Torres, R.: Conservación de recursos genéticos ovinos en la raza Xisqueta: caracterización estructural, racial y gestión de la diversidad en programas "in situ". $\mathrm{Ph}$ D Thesis. Universitat Autónoma de Barcelona, Barcelona (2006)

26. Watson, A.: Animal Populations in Relation to Their Food Resources. Blackwell Scientific Publications, Oxford (1970) 


\section{Appendix}

Table 1. Number of animals presents in the Catalan Pyrenees between 1994-1998

\begin{tabular}{|l|c|c|}
\hline Species & 1994 & 2008 \\
\hline Bearded Vulture pairs & 20 & 37 \\
\hline Pyrenean Chamois & 9000 & 12000 \\
\hline Red deer & 1000 & 5500 \\
\hline Fallow deer & 600 & 1500 \\
\hline Roe deer & 1000 & 10000 \\
\hline Sheep & 15000 & 200000 \\
\hline
\end{tabular}

Table 2. Natural constants used in the model

\begin{tabular}{|l|c|c|c|c|c|c|c|c|}
\hline Species & $I_{1}$ & $I_{2}$ & $I_{3}$ & $I_{4}$ & $I_{5}$ & $I_{6}$ & $I_{7}$ & $I_{8}$ \\
\hline Bearded Vulture & 1 & 8 & 20 & 21 & 38 & 6 & 12 & 50 \\
\hline Pyrenean Chamois & 1 & 2 & 18 & 18 & 75 & 60 & 6 & 55 \\
\hline Red Deer & 1 & 2 & 17 & $17-20$ & 75 & 34 & 6 & 50 \\
\hline Fallow Deer & 1 & 2 & 12 & 12 & 55 & 50 & 6 & 75 \\
\hline Roe Deer & 1 & 1 & 10 & 10 & 100 & 58 & 6 & 67 \\
\hline Sheep & 1 & 2 & 8 & 8 & 75 & 15 & 3 & 96 \\
\hline
\end{tabular}

Table 3. Descriptive variables used to model the ecosystem

\begin{tabular}{|c|c|c|c|c|c|c|c|}
\hline Species & $\begin{array}{c}\text { Weigh } \\
\text { Male } \\
\\
\mathrm{kg} \\
\end{array}$ & \begin{tabular}{|c|} 
Weigh \\
Female \\
kg \\
\end{tabular} & $\begin{array}{c}\text { Percentage } \\
\text { Female }\end{array}$ & $\begin{array}{c}\text { Average } \\
\text { weigh } \\
\mathrm{kg}\end{array}$ & $\begin{array}{c}\text { Biomass: } \\
\text { bone } \\
\text { adult } \\
\text { kg }\end{array}$ & \begin{tabular}{|c|} 
Biomass: \\
bone \\
young \\
$\mathrm{kg}$
\end{tabular} & $\begin{array}{l}\text { Kg accessible } \\
\text { by B. Vulture } \\
\text { (adult/young) }\end{array}$ \\
\hline \begin{tabular}{|l} 
Bearded \\
Vulture
\end{tabular} & 5 & 6.5 & 50 & 5.75 & - & - & - \\
\hline $\begin{array}{l}\text { Pyrenean } \\
\text { Chamois }\end{array}$ & 28 & 32 & 50 & 30 & 6 & 3 & $6 / 3$ \\
\hline $\begin{array}{l}\text { Red Deer } \\
\text { Female }\end{array}$ & - & 75 & - & 75 & 15 & 7.5 & $15 / 7.5$ \\
\hline $\begin{array}{l}\text { Red Deer } \\
\text { Male }\end{array}$ & 120 & - & - & 120 & 24 & 12 & $24 / 12$ \\
\hline Fallow Deer & 63 & 42 & 80 & 46 & 9 & 4.5 & $2 / 1$ \\
\hline \begin{tabular}{|l|} 
Roe Deer \\
\end{tabular} & 27 & 23 & 66 & 24 & 5 & 2.5 & $1 / 0.5$ \\
\hline Sheep & 42 & 35 & 97 & 35.2 & 7 & 3.5 & $7 / 3.5$ \\
\hline
\end{tabular}


Table 4. Constants used in the $\mathrm{P}$ system based model

\begin{tabular}{|l|c|c|c|c|c|c|c|c|c|c|c|c|c|c|c|c|}
\hline Species & $i$ & $k_{i, 1}$ & $k_{i, 2}$ & $k_{i, 3}$ & $k_{i, 4}$ & $k_{i, 5}$ & $k_{i, 6}$ & $k_{i, 7}$ & $k_{i, 8}$ & $k_{i, 9}$ & $k_{i, 10}$ & $k_{i, 11}$ & $k_{i, 12}$ & $k_{i, 13}$ & $k_{i, 14}$ & $k_{i, 15}$ \\
\hline $\begin{array}{l}\text { Bearded } \\
\text { Vulture }\end{array}$ & 1 & 1 & 8 & 20 & 21 & 0.38 & 0.04 & 0 & 0.06 & 1 & 0.12 & 0 & 0 & 0.50 & 460 & 1 \\
\hline $\begin{array}{l}\text { Pyrenean } \\
\text { Chamois }\end{array}$ & 2 & 1 & 2 & 18 & 18 & 0.75 & - & 0 & 0.60 & 1 & 0.06 & 6 & 12 & 0.55 & - & 0 \\
\hline $\begin{array}{l}\text { Red Deer } \\
\text { Female }\end{array}$ & 3 & 1 & 2 & 17 & 17 & 0.75 & - & 0 & 0.34 & 1 & 0.06 & 15 & 30 & 1.00 & - & 0 \\
\hline $\begin{array}{l}\text { Red Deer } \\
\text { Male }\end{array}$ & 4 & 1 & 2 & - & 20 & - & - & 0 & 0.34 & 1 & 0.36 & 24 & 48 & 0 & - & 0 \\
\hline Fallow Deer & 5 & 1 & 2 & 12 & 12 & 0.55 & - & 0 & 0.50 & 1 & 0.06 & 2 & 4 & 0.75 & - & 0 \\
\hline Roe Deer & 6 & 1 & 1 & 10 & 10 & 1.00 & - & 0 & 0.58 & 1 & 0.06 & 1 & 2 & 0.67 & - & 0 \\
\hline Sheep & 7 & 1 & 2 & 8 & 8 & 0.75 & - & 0.57 & 0.15 & 0 & 0.03 & 7 & 14 & 0.96 & - & 0 \\
\hline
\end{tabular}

Table 5. Estimation of number of animals per age in 1994

\begin{tabular}{|l|l|l|l|l|l|l|}
\hline Age & Bearded V. Chamois & Red d. female & Red d. male & Fallow deer & Roe deer & Sheep \\
\hline
\end{tabular}

\begin{tabular}{|c|c|c|c|c|c|c|c|}
\hline 1 & 0 & 741 & 167 & 58 & 83 & 121 & 20832 \\
\hline 2 & 0 & 740 & 133 & 44 & 73 & 121 & 20208 \\
\hline 3 & 0 & 668 & 107 & 35 & 69 & 121 & 19601 \\
\hline 4 & 0 & 667 & 85 & 28 & 63 & 121 & 19014 \\
\hline 5 & 0 & 667 & 68 & 23 & 59 & 109 & 18443 \\
\hline 6 & 0 & 596 & 41 & 14 & 55 & 108 & 17890 \\
\hline 7 & 0 & 594 & 33 & 11 & 51 & 108 & 17353 \\
\hline 8 & 2 & 518 & 26 & 9 & 47 & 96 & 16659 \\
\hline 9 & 2 & 517 & 21 & 7 & 35 & 96 & 0 \\
\hline 10 & 2 & 444 & 17 & 5 & 33 & 0 & 0 \\
\hline 11 & 2 & 444 & 13 & 5 & 30 & 0 & 0 \\
\hline 12 & 2 & 444 & 11 & 4 & 0 & 0 & 0 \\
\hline 13 & 2 & 373 & 9 & 3 & 0 & 0 & 0 \\
\hline 14 & 1 & 373 & 7 & 2 & 0 & 0 & 0 \\
\hline 15 & 1 & 372 & 5 & 2 & 0 & 0 & 0 \\
\hline 16 & 1 & 296 & 4 & 1 & 0 & 0 & 0 \\
\hline 17 & 1 & 296 & 3 & 1 & 0 & 0 & 0 \\
\hline 18 & 1 & 252 & 0 & 0 & 0 & 0 & 0 \\
\hline 19 & 1 & 0 & 0 & 0 & 0 & 0 & 0 \\
\hline 20 & 1 & 0 & 0 & 0 & 0 & 0 & 0 \\
\hline 21 & 1 & 0 & 0 & 0 & 0 & 0 & 0 \\
\hline
\end{tabular}


Table 6. Estimation of number of animals per age in 2008

\begin{tabular}{|c|c|c|c|c|c|c|c|}
\hline Age & Bearded V. & Chamois & Red d. female & Red d. male & Fallow deer & Roe deer & Sheep \\
\hline 1 & 0 & 988 & 978 & 254 & 125 & 1210 & 27776 \\
\hline 2 & 0 & 987 & 780 & 192 & 110 & 1207 & 26944 \\
\hline 3 & 0 & 890 & 625 & 154 & 103 & 1207 & 26135 \\
\hline 4 & 0 & 889 & 500 & 124 & 95 & 1207 & 25352 \\
\hline 5 & 0 & 889 & 400 & 99 & 89 & 1085 & 24591 \\
\hline 6 & 0 & 795 & 240 & 60 & 83 & 1083 & 23854 \\
\hline 7 & 0 & 792 & 195 & 48 & 77 & 1083 & 23137 \\
\hline 8 & 6 & 690 & 155 & 38 & 71 & 959 & 22212 \\
\hline 9 & 6 & 689 & 123 & 30 & 52 & 959 & 0 \\
\hline 10 & 6 & 592 & 97 & 24 & 50 & 0 & 0 \\
\hline 11 & 6 & 592 & 78 & 20 & 45 & 0 & 0 \\
\hline 12 & 5 & 592 & 62 & 16 & 0 & 0 & 0 \\
\hline 13 & 5 & 497 & 50 & 12 & 0 & 0 & 0 \\
\hline 14 & 5 & 497 & 40 & 10 & 0 & 0 & 0 \\
\hline 15 & 5 & 496 & 32 & 8 & 0 & 0 & 0 \\
\hline 16 & 5 & 395 & 25 & 6 & 0 & 0 & 0 \\
\hline 17 & 5 & 394 & 20 & 5 & 0 & 0 & 0 \\
\hline 18 & 5 & 336 & 0 & 0 & 0 & 0 & 0 \\
\hline 19 & 5 & 0 & 0 & 0 & 0 & 0 & 0 \\
\hline 20 & 5 & 0 & 0 & 0 & 0 & 0 & 0 \\
\hline 21 & 5 & 0 & 0 & 0 & 0 & 0 & 0 \\
\hline
\end{tabular}

Table 7. Number of animals produced by the simulator

\begin{tabular}{|c|c|c|c|c|c|c|c|}
\hline Year & $\begin{array}{c}\text { Bearded } \\
\text { Vulture }\end{array}$ & $\begin{array}{c}\text { Pyrenean } \\
\text { Chamois }\end{array}$ & $\begin{array}{c}\text { Pyrenean } \\
\text { Chamois }\end{array}$ & $\begin{array}{c}\text { Red } \\
\text { Deer }\end{array}$ & $\begin{array}{c}\text { Fallow } \\
\text { Deer }\end{array}$ & $\begin{array}{c}\text { Roe } \\
\text { Deer }\end{array}$ & Sheep \\
\hline 1994 & 20 & 9000 & & 1000 & 600 & 1000 & 150000 \\
\hline 1995 & 21 & 9541 & & 1115 & 667 & 1213 & 152074 \\
\hline 1996 & 21 & 10023 & & 1263 & 710 & 1371 & 153951 \\
\hline 1997 & 22 & 10590 & & 1432 & 758 & 1568 & 156183 \\
\hline 1998 & 23 & 11121 & & 1617 & 808 & 1812 & 158571 \\
\hline 1999 & 24 & 11718 & & 1834 & 859 & 2106 & 161318 \\
\hline 2000 & 25 & 12366 & & 2087 & 908 & 2469 & 164391 \\
\hline 2001 & 27 & 13032 & & 2368 & 967 & 2906 & 167914 \\
\hline 2002 & 28 & 13767 & & 2705 & 1032 & 3459 & 171940 \\
\hline 2003 & 29 & 14597 & & 3067 & 1111 & 4132 & 174713 \\
\hline 2004 & 31 & 15488 & 10000 & 3470 & 1202 & 4969 & 177973 \\
\hline 2005 & 33 & 16468 & 10594 & 3917 & 1297 & 5883 & 181300 \\
\hline 2006 & 35 & 17508 & 11133 & 4437 & 1399 & 6974 & 184790 \\
\hline 2007 & 36 & 18647 & 11709 & 5004 & 1495 & 8272 & 188357 \\
\hline $\mathbf{2 0 0 8}$ & $\mathbf{3 8}$ & $\mathbf{1 9 8 6 6}$ & $\mathbf{1 2 2 9 7}$ & $\mathbf{5 6 3 1}$ & $\mathbf{1 6 0 2}$ & $\mathbf{9 7 7 4}$ & $\mathbf{1 9 2 0 9 7}$ \\
\hline
\end{tabular}

